\title{
Elevated hydrogen peroxide and decreased catalase and glutathione peroxidase protection are associated with aging sarcopenia
}

Melanie J Sullivan-Gunn ${ }^{1}$ and Paul A Lewandowski ${ }^{2^{*}}$

\begin{abstract}
Background: Sarcopenia is the progressive loss of skeletal muscle that contributes to the decline in physical function during aging. A higher level of oxidative stress has been implicated in aging sarcopenia. The current study aims to determine if the higher level of oxidative stress is a result of increased superoxide $\left(\mathrm{O}_{2}{ }^{-}\right)$production by the NADPH oxidase (NOX) enzyme or decrease in endogenous antioxidant enzyme protection.

Methods: Female Balb/c mice were assigned to 4 age groups; 6, 12, 18 and 24 months. Body weight and animal survival rates were recorded over the course of the study. Skeletal muscle tissues were collected and used to measure NOX subunit mRNA, $\mathrm{O}_{2}^{-}$levels and antioxidant enzymes.

Results: Key subunit components of NOX expression were elevated in skeletal muscle at 18 months, when sarcopenia was first evident. Increased superoxide dismutase 1 (SOD1) activity suggests an increase in $\mathrm{O}_{2}^{-}$ dismutation and this was further supported by elevated levels of hydrogen peroxide $\left(\mathrm{H}_{2} \mathrm{O}_{2}\right)$ and decline in catalase and glutathione peroxidase (GPX) antioxidant protection in skeletal muscle at this time. NOX expression was also higher in skeletal muscle at 24 months, however this was coupled with elevated levels of $\mathrm{O}_{2}{ }^{-}$and a decline in SOD1 activity, compared to 6 and 12 months but was not associated with further loss of muscle mass.

Conclusions: While the source of ROS in sarcopenic muscle remains unknown, this study provides evidence that the NOX enzyme could be involved in ROS production by regulating superoxide in ageing muscles. This study also suggests that $\mathrm{H}_{2} \mathrm{O}_{2}$ is the key ROS in the onset of sarcopenia and that the decline in antioxidant protection by catalase and GPx is indicative of antioxidant dysfunction and may therefore be a major contributing factor in the development or onset of sarcopenia. Furthermore, the changes in ROS and antioxidant activity after sarcopenia was first evident gives some evidence for a compensatory mechanism, in response to insult, in order to maintain muscle integrity.
\end{abstract}

Keywords: Sarcopenia, NADPH oxidase, Superoxide, Hydrogen Peroxide, Antioxidants

\section{Background}

One of the most dramatic phenotypic changes during aging is sarcopenia [1,2]. Sarcopenia is characterised by a significant loss of skeletal muscle mass [3] at a rate of $5 \%$ per decade, starting in the fourth decade [4] with a prevalence of $5-13 \%$ in people $60-70$ years of age and $11-50 \%$ of people over 80 years [5]. Consequently, the progressive age-associated loss of muscle mass leads to significant weakness, frailty and decreased quality of life [6]. It has

\footnotetext{
* Correspondence: paul.lewandowski@deakin.edu.au

${ }^{2}$ School of Medicine, Deakin University, Geelong 3217, Vic, Australia

Full list of author information is available at the end of the article
}

recently been reported that sarcopenia causes significant frailty in the elderly that any stressor leads to a poor outcome, disability and mortality [5] despite age, clinical and functional variability [7].

The free radical theory of aging postulates that endogenous reactive oxygen species (ROS) cause progressive cellular damage and that incomplete repair leads to an accumulation over time [8]. ROS are generated in skeletal muscle as by-products of cellular metabolism, but are capable of exceeding beyond normal cellular levels, during exercise [1] and in disease [9-11] and the

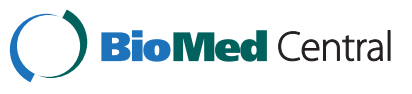

(c) 2013 Sullivan-Gunn and Lewandowski; licensee BioMed Central Ltd. This is an open access article distributed under the terms of the Creative Commons Attribution License (http://creativecommons.org/licenses/by/2.0), which permits unrestricted use, distribution, and reproduction in any medium, provided the original work is properly cited. 
ability of cells to actively detoxify ROS becomes less efficient over time [12].

The knowledge that the NADPH oxidase (NOX) enzyme is a primary superoxide $\left(\mathrm{O}_{2}{ }^{-}\right)$producing system [13] has brought about much speculation for its role in skeletal muscle. The NOX catalytic subunit NOX2 [9], associated subunit components, $\mathrm{p} 22^{\text {phox }}, \mathrm{p} 40^{\text {phox }}, \mathrm{p} 47^{\text {phox }}$ and p $67^{\text {phox }}$ [14], GTP binding protein Rac1 [15] and the NOX2 homologue NOX4, have been found in skeletal muscle tissue [16]. Although limited research exists, aging studies have demonstrated an age-associated increase in ROS as a consequence of NOX2 enzyme up regulation [11] and activity [17], and decreases in endothelial dysfunction and vascular aging have been reported in NOX2 deficient mice $[18,19]$. Overexpression of NOX4 has been proposed to lead to cellular senescence in fibroblasts [20] and degenerative dysfunction associated with aging [21]. Furthermore, NOX has been identified as the key source of $\mathrm{O}_{2}^{-}$that contributes to cardiovascular aging [11] and other age-associated conditions such as diabetes [22], arthritis [23], cataracts [24], Alzheimer's disease [25] and motorneuron dysfunction [10].

The high metabolic activity of skeletal muscle makes it particularly vulnerable to excess ROS production and oxidative stress [26]. Antioxidant enzymes are therefore important in skeletal muscle and contrasting studies have propose both a compensatory increase in antioxidant activity [27] as well as evidence to suggest antioxidant dysfunction [12] during aging. Superoxide dismutase (SOD) is responsible for the dismutation of $\mathrm{O}_{2}{ }^{-}$and elimination of cellular oxidative stress. The absence of the cytosolic SOD1 isoform is known to significantly decrease lifespan [28] and more recently, high levels of oxidative stress and accelerated sarcopenia due to $\mathrm{O}_{2}{ }^{-}$induced neuromuscular degeneration and mitochondrial dysfunction has been shown in SOD1 deficient mice [29-31].

Oxidative stress is recognised as a major contributor to aging and age-associated disease $[10,29,32]$ and evidence suggests its involvement in the development of sarcopenia [1]. However, the key contributors to oxidative stress in skeletal muscle during aging and changes within these systems throughout the lifespan, remains undefined. Therefore, this study aims to investigate the NOX and antioxidant enzyme systems in aging skeletal muscle. In particular, this study aims to determine changes in the NOX proteins; NOX2, NOX4, p22 $2^{\text {phox }}$, $\mathrm{p} 40^{\text {phox }}$, $\mathrm{p} 47^{\text {phox }}$, p67 $7^{\text {phox }}$ and Rac1, $\mathrm{O}_{2}{ }^{-}$and $\mathrm{H}_{2} \mathrm{O}_{2}$ levels and associated antioxidants; SOD isoforms, catalase and GPx, in skeletal muscle during aging.

\section{Methods}

\section{Animal model of aging sarcopenia}

All animal procedures carried out in this study were approved by the Victoria University Animal Ethics Committee
(AEETH 14/05). Female Balb/c mice were assigned to 4 age groups; 6, 12, 18 and 24 months of age and maintained under controlled environmental conditions; 12 hour light/ dark cycle, $21 \pm 2 \mathrm{C}, 30 \%$ humidity, in conventional cages with ad libitum access to standard chow and water. Body weight measurements and animal survival rates were recorded over the course of the study. Skeletal muscle tissues were collected from $6(n=16), 12(n=18), 18(n=12)$ and $24(n=12)$ month old mice and immediately snap frozen in liquid nitrogen and stored at $-80^{\circ} \mathrm{C}$ for later use.

\section{Detection of $\mathrm{O}_{2}^{-}$by DHE fluorescence staining}

Skeletal muscle $\mathrm{O}_{2}^{-}$was measured by histological Dihydroethidium (DHE) fluorescence examination. DHE is cell permeable and reacts with $\mathrm{O}_{2}{ }^{-}$converting DHE into ethidium fluorescence [33]. DHE $(5 \mu \mathrm{m} / \mathrm{L})$ was applied to quadriceps cryosections $(5 \mu \mathrm{m})$ and incubated in a light protected oven at $37^{\circ} \mathrm{C}$ for 30 minutes. The DHE was washed from the sections with PBS and fluorescence was assessed using Axiocam HBO 50/AC fluorescence microscopy (Zeiss, Germany). The intensity of ethidium fluorescence detection of $\mathrm{O}_{2}{ }^{-}$was measured with MCID imaging software (Imaging Research Inc. Australia) with excitation at $480 \mathrm{~nm}$ and emission at $560 \mathrm{~nm}$. Values represent the area of fluorescence, above a specified threshold, expressed as a percentage of the total area of the muscle cross-section [34].

\section{Reverse transcription-real-time PCR}

RNA was extracted from frozen quadriceps muscle using Tri Reagent (Molecular Research Centre, USA), according to the manufacturer's protocol. Total RNA concentration was determined spectrophotometrically at $260 \mathrm{~nm}$. Firststrand cDNA was generated from $1 \mu \mathrm{g}$ RNA using AMV RT (Promega, Australia). Pre-designed TaqMan Gene Expression Assays (Applied Biosystems, USA) were used containing specific primers and probes for the gene of interest. Real-time PCR was performed using Applied Biosystems 7500 detection system following manufacturer's instructions (Applied Biosystems, USA) and PCR reactions were performed using TaqMan Gene Expression Master Mix (Applied Biosystems, USA). To compensate for variations in input RNA amounts and efficiency of reverse transcription, $18 \mathrm{~s}$ ribosomal mRNA was quantified and all results were normalised to these values. Fluorescent emission data was captured and mRNA levels were analysed using the critical threshold value $\left(C_{\mathrm{T}}\right)$ [35].

\section{Protein electrophoresis and western blotting}

Protein was extracted from frozen quadriceps muscle homogenized in ice-cold radio- immunoprecipitation assay (RIPA) buffer containing Tris $\mathrm{HCl}(50 \mathrm{mmol} / \mathrm{L} ; \mathrm{pH} 7.4)$, $\mathrm{NaCl}(150 \mathrm{mmol} / \mathrm{L}), \mathrm{NP}-40$ (1\%), sodium deoxycholate $(0.5 \%)$ and SDS $(0.1 \%)$ and centrifuged at $13,000 \times \mathrm{g}$ for 
15 minutes at $4^{\circ} \mathrm{C}$, to remove insoluble material. The protein concentration was determined by the Bradford method (Bio-Rad) and equal amounts of protein were separated by SDS-PAGE and transferred to polyvinylidene difluoride membranes. The membranes were blocked for 2 hours at room temperature in Tris-buffered saline containing Tris- $\mathrm{HCl}(20 \mathrm{mM} ; \mathrm{pH}$ 7.6) $\mathrm{NaCl}(137 \mathrm{mM})$ and Tween $20(0.1 \%)$ with 5\% BSA and probed with primary antibodies for either NOX2 (gp91 $\left.{ }^{\text {phox }}\right), \mathrm{p} 40^{\text {phox }}$, p67 $7^{\text {phox }}$ or GAPDH (1:200; SantaCruz Biotechnology) overnight at $4^{\circ} \mathrm{C}$. Antibody binding was detected using horseradish peroxidase conjugated secondary antibody (1:50,000; SantaCruz Biotechnology). The protein bands were detected by SuperSignal West Dura chemiluminescence reagents (Thermo Scientific). The LAS 4000 Imaging System (Fujifilm Life Science, USA) was used to visualize protein bands and densitometry was performed with MultiGauge software (Fujifilm Life Science, USA). To compensate for variation in protein loading the relative density of immunoreactive bands were normalized to the density of the corresponding bands for GAPDH.

\section{Antioxidant enzyme activity and hydrogen peroxide assays}

Spectrophotometric assay kits were used to measure SOD (Cayman-706002), catalase (Cayman-707002) and GPx (Cayman-703102) activity and $\mathrm{H}_{2} \mathrm{O}_{2}$ (Cayman600050) levels, in muscle homogenates. Frozen muscle pieces (100 mg) were placed in ice-cold HEPES buffer (20 mM) containing EGTA (1 mM), mannitol (210 mM) and sucrose $(70 \mathrm{mM})$ and adjusted to a $\mathrm{pH}$ of 7.2 $(10 \mathrm{ml} / \mathrm{g})$. Muscle aliquots were homogenised in buffer, using a glass on glass homogeniser, and centrifuged at $1,500 \times \mathrm{g}$ for $5 \mathrm{~min}$ at $4^{\circ} \mathrm{C}$ to remove insoluble connective tissue. For the detection of SOD1 and SOD2, cytosolic and mitochondrial fractions were separated. The supernatant was centrifuged at $10,000 \times \mathrm{g}$ for $5 \mathrm{~min}$ at $4^{\circ} \mathrm{C}$, and the resulting supernatant, containing the cytosolic fraction, was collected for SOD1 enzyme analysis. The remaining pellet containing the mitochondrial fraction was resuspended and homogenised in ice cold HEPES buffer $(20 \mathrm{mM})$ for SOD2 enzyme analysis. SOD1 and SOD2 activity was measured in cytosolic and mitochondrial muscle fractions, respectively. The amount of enzyme activity and $\mathrm{H}_{2} \mathrm{O}_{2}$ levels were calculated and standardised for protein using the Bradford method (Bio-Rad).

\section{Statistical analysis}

Statistical analysis was performed using SPSS statistical package (version 15.0). Results were expressed as mean \pm SEM. Differences were determined by one-way ANOVA with Tukey HSD as posthoc and results were considered statistically significant if $p$ values $\leq 0.05$.

\section{Results}

Establishment of murine model of aging sarcopenia

Survival rates of female Balb/c mice began to decline at approximately 14 months of age with a $60 \%$ survival rate in the 18 month group and a 50\% survival rate in the 24 month group (Figure 1). Skeletal muscle mass and muscle mass as ratio to body weight increased at 12 months of age compared to 6 months of age $(p<0.001$, Table 1$)$ and decreased at $18(p<0.001)$ and $24(p<0.001)$ months of age compared to 12 months (Table 1 ).

\section{$\mathrm{O}_{2}{ }^{-}$Levels in skeletal muscle of aging mice}

Ethidium fluorescence was elevated throughout the quadriceps muscle from 24 month old mice compared to $6(p=0.001)$ and $12(p<0.001)$ month old mice (Figure 2$)$. Similar levels of fluorescence were observed between the other age groups (Figure 2).

\section{MRNA expression of Pro-oxidant and antioxidant enzymes in skeletal muscle of aging mice}

The mRNA expression of the NOX enzyme subunits showed differential expression in skeletal muscle during aging. The catalytic NOX2 subunit was higher in the quadriceps muscle at 18 months compared to the younger $6(p=0.027)$ and $12(p=0.023)$ month old mice together with the older $24(p=0.047)$ month old mice (Table 2). Similarly, the mRNA expression of the NOX2 regulatory subunit, $\mathrm{p} 40^{\text {phox }}$ was higher in the quadriceps muscle at 18 months compared to the younger 6 month old mice $(p=0.030$, Table 2$)$. Interestingly, the mRNA expression of the catalytic NOX2 type subunit $\mathrm{p} 67^{\text {phox }}$

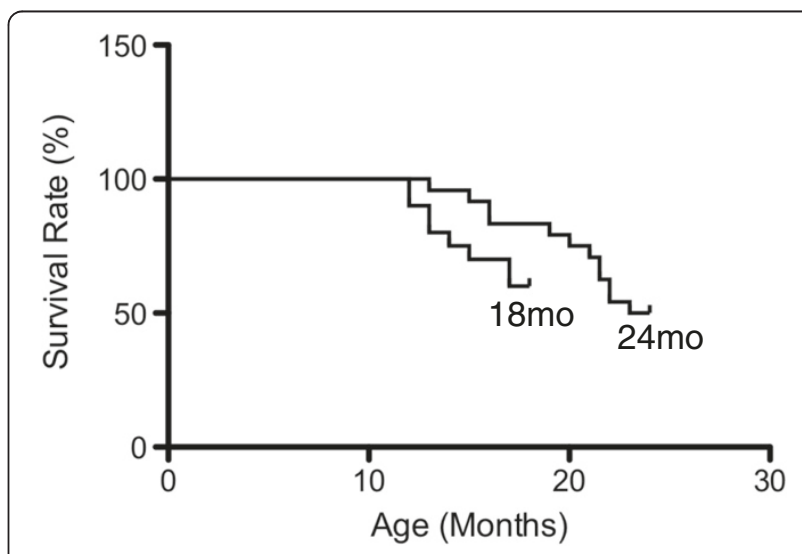

Figure 1 Animal survival rates in the 18 and 24 month old age groups, expressed as a percentage of live animals for each group. Female BALB/c mice purchased at 9 months of age were assigned to the 18 month old group $(n=20)$ and 24 month old group $(n=24)$. Animal survival declined from approximately 14 months of age in both groups and continued to decline thereafter. A $60 \%$ decline in animal survival was observed in the 18 month old group $(18 \mathrm{~m} / \mathrm{o})$, while a $50 \%$ decline in survival rate was observed the 24 month old group ( $24 \mathrm{~m} / \mathrm{o}$ ). 
Table 1 Body weight and quadriceps muscle weights

\begin{tabular}{lcccc}
\hline & \multicolumn{2}{c}{ Age (months) } \\
\hline & $\mathbf{6}(\boldsymbol{n}=\mathbf{1 6})$ & $\mathbf{1 2}(\boldsymbol{n}=\mathbf{1 8})$ & $\mathbf{1 8}(\boldsymbol{n}=\mathbf{1 2})$ & $\mathbf{2 4}(\boldsymbol{n}=\mathbf{1 2})$ \\
Body weight $(\mathrm{g})$ & $30 \pm 1.8$ & $27 \pm 2.2$ & $28 \pm 1.3$ & $28 \pm 1.3$ \\
Quadriceps weight $(\mathrm{g})$ & $0.15 \pm 0.02$ & $0.18 \pm 0.01^{\text {acd }}$ & $0.15 \pm 0.02$ & $0.16 \pm 0.01$ \\
Body weight/quadriceps weight ratio & $5.08 \pm 0.59$ & $6.15 \pm 1.72^{\text {acd }}$ & $5.45 \pm 0.38$ & $5.55 \pm 0.52$ \\
\hline
\end{tabular}

The values represent the mean \pm SEM.

Statistically significant differences $(P<0.05)$ between groups are indicated by lower case letters, where ${ }^{\mathrm{a}} 6 \mathrm{~m} / \mathrm{o},{ }^{\mathrm{C}} 18 \mathrm{~m} / \mathrm{o}$ and ${ }^{\mathrm{d}} 24 \mathrm{~m} / \mathrm{o}$.

was higher in the quadriceps muscle at 24 months compared to the younger $6(p=0.007), 12(p=0.001)$ and 18 $(p=0.032)$ month old mice (Table 2$)$. The mRNA expression of the NOX2 subunits, $\mathrm{p} 22^{\text {phox }}$ and $\mathrm{p} 47^{\text {phox }}$ and NOX2 subunit regulator, Rac1 were similar in the quadriceps muscle from all age groups. Like the NOX2 subunit itself, the mRNA expression of the catalytic NOX2 homologue, NOX4 was higher in the quadriceps muscle at 18 months compared to 6 months $(p=0.021$, Table 2).
The antioxidant enzymes also showed differential expression in skeletal muscle during aging. The mRNA expression of the cytosolic SOD1 and mitochondrial SOD2 antioxidant enzymes were higher in the quadriceps muscle at 24 months compared to the younger $6(p=$ $0.005, p=0.016), 12(p=0.010, p=0.006)$ and $18(p=$ $0.043, p=0.012$ ) month old mice (Table 2). Similarly, the mRNA expression of the antioxidant enzyme GPx was higher in the quadriceps muscle at 24 months compared to the younger 6 month old mice $(p=0.031$, Table 2$)$.
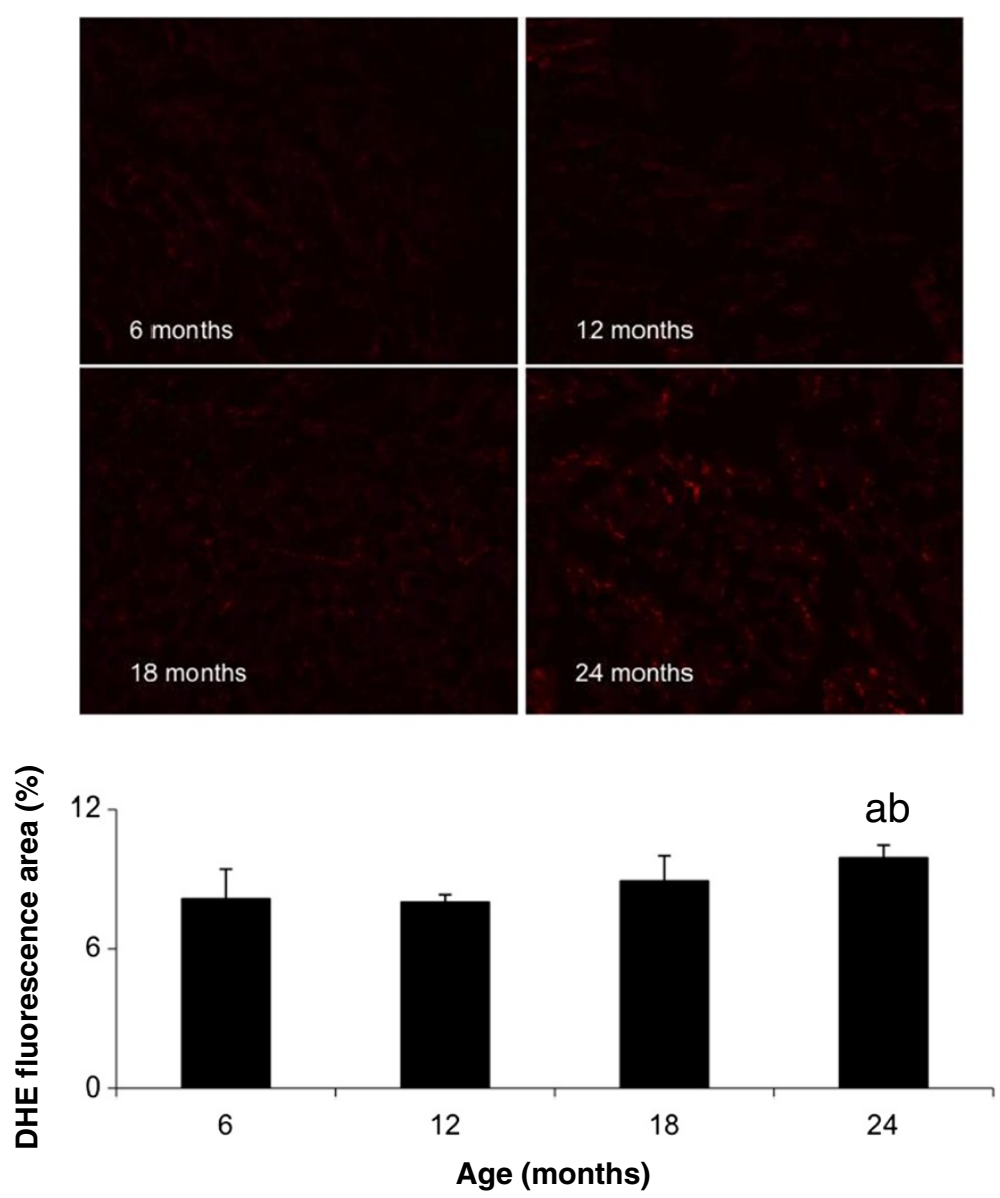

Figure $2 \mathrm{O}_{2}^{-}$levels in aging skeletal muscle, by histological DHE examination, values represent the area of fluorescence, above a specified threshold, expressed as a percentage of the total area of the muscle cross-section. The values represent the mean $\pm S E M$. Statistically significant differences $(P<0.05)$ between groups are indicated by lower case letters, where $a=6 \mathrm{~m} / \mathrm{o}, \mathrm{b}=12 \mathrm{~m} / \mathrm{o}, \mathrm{c}=18 \mathrm{~m} / \mathrm{o}$ and $d=24 \mathrm{~m} / \mathrm{o}$. 
Table 2 Relative gene expression in aging skeletal muscle

\begin{tabular}{|c|c|c|c|c|}
\hline & & Age & (months) & \\
\hline & $6(n=16)$ & $12(n=18)$ & $18(n=12)$ & $24(n=12)$ \\
\hline $\begin{array}{l}\text { Gene } \\
\text { expression (AU) }\end{array}$ & & & & \\
\hline NOX2 & $13.1 \pm 2.9$ & $11.0 \pm 3.1$ & $110 \pm 14.7^{\mathrm{abd}}$ & $23.0 \pm 4.4$ \\
\hline p22 phox & $17.8 \pm 3.7$ & $26.5 \pm 7.0$ & $25.1 \pm 9.4$ & $48.7 \pm 10.3$ \\
\hline $\mathrm{p} 40^{\text {phox }}$ & $14.0 \pm 4.9$ & $25.2 \pm 8.7$ & $57.7 \pm 16.9^{a}$ & $42.9 \pm 8.9$ \\
\hline $\mathrm{p} 47^{\text {phox }}$ & $3.1 \pm 0.6$ & $4.8 \pm 1.4$ & $16.4 \pm 7.9$ & $4.2 \pm 1.2$ \\
\hline p67 phox & $72.9 \pm 13.4$ & $41.1 \pm 8.9$ & $103 \pm 33.0$ & $272 \pm 71^{\mathrm{abc}}$ \\
\hline NOX4 & $1.5 \pm 0.3$ & $4.3 \pm 1.0$ & $9.2 \pm 3.2^{a}$ & $5.1 \pm 1.3$ \\
\hline Rac1 & $1.2 \pm 1.1$ & $3.91 \pm 0.9$ & $2.9 \pm 1.3$ & $5.3 \pm 0.8$ \\
\hline SOD1 & $16.1 \pm 5.2$ & $19.3 \pm 5.1$ & $33.6 \pm 11.0$ & $69.6 \pm 15.6^{\mathrm{abc}}$ \\
\hline SOD2 & $7.9 \pm 2.1$ & $6.6 \pm 1.5$ & $6.7 \pm 2.6$ & $19.5 \pm 4.0^{\mathrm{abc}}$ \\
\hline SOD3 & $1.7 \pm 0.4$ & $1.51 \pm 0.2$ & $2.5 \pm 1.3$ & $2.9 \pm 0.8$ \\
\hline Gpx & $16.5 \pm 4.3$ & $42.2 \pm 10.2$ & $56.4 \pm 22.7$ & $40.5 \pm 6.0^{a}$ \\
\hline Catalase & $19.4 \pm 5.1$ & $28.1 \pm 8.1$ & $34.4 \pm 10.3$ & $52.0 \pm 9.0$ \\
\hline
\end{tabular}

The values represent the mean \pm SEM, with all results normalised to $18 \mathrm{~s}$ ribosomal mRNA. Statistically significant differences $(P<0.05)$ between groups are indicated by lower case letters, where ${ }^{\mathrm{a}} 6 \mathrm{~m} / \mathrm{o},{ }^{\mathrm{b}} 12 \mathrm{~m} / \mathrm{o},{ }^{\mathrm{c}} 18 \mathrm{~m} / \mathrm{o}$ and ${ }^{\mathrm{d}} 24 \mathrm{~m} / \mathrm{o}$.

There was no change in the mRNA expression of the extracellular SOD3 antioxidant enzyme and catalase in the quadriceps muscle from all age groups (Table 2).

\section{Protein levels of NOX2 enzyme subunits in skeletal muscle of aging mice}

Changes in the mRNA levels of the key NOX2 enzyme subunits; NOX2, $\mathrm{p} 40^{\text {phox }}$ and $\mathrm{p} 67^{\text {phox }}$ lead to further analysis of protein expression. The protein expression of the regulatory NOX2 enzyme subunit $\mathrm{p} 40^{\text {phox }}$ was lower in the quadriceps muscle at 24 months compared to the younger $6(\mathrm{p}=0.039)$ and $18(\mathrm{p}=0.001)$ month old mice (Figure 3). However, the protein expression of the catalytic NOX2 enzyme subunit p67 $7^{\text {phox }}$ was higher in the quadriceps muscle at 24 months compared to the younger $6(\mathrm{p}=0.027)$ and $18(\mathrm{p}=0.004)$ month old mice (Figure 3$)$ and NOX2 protein expression was similar in all age groups (Figure 3).

\section{Antioxidant enzyme activity and hydrogen peroxide levels in skeletal muscle of aging mice}

The changes in SOD mRNA expression lead to the investigation of SOD enzyme activity in skeletal muscle during aging. SOD1 activity levels were elevated in the quadriceps muscle at 18 months compared to the younger $6(p<0.001), 12(p<0.001)$ and older $24(p=0.011)$ month old mice (Table 3), and SOD1 activity in the quadriceps muscle at 12 months compared to $6(p=0.005), 18(p<$ $0.001)$ and $24(p<0.001)$ months (Table 3). Additionally, SOD2 activity levels were lower in the quadriceps muscle at 24 months compared to the younger $6(p<0.001)$ and $12(p<0.001)$ month old mice (Table 3$)$.

Changes in SOD antioxidant activity for the dismutation of $\mathrm{O}_{2}^{-}$to $\mathrm{H}_{2} \mathrm{O}_{2}$ lead to further investigation of the $\mathrm{H}_{2} \mathrm{O}_{2}$ specific antioxidant enzymes, GPx and catalase. GPx activity levels were lower in skeletal muscle at 18 months compared to the younger $6(p=0.001), 12$ $(p<0.001)$ and older 24. $(p=0.004)$ month old mice (Table 3). Similarly, catalase activity levels were lower in the quadriceps muscle at 18 months compared to the younger $12 \quad(p<0.001)$ and older $24 \quad(p=0.004)$ month old mice, and higher at 12 months compared to 6 months $(p=0.043)$ (Table 3).

Elevated levels of $\mathrm{O}_{2}{ }^{-}$and increased SOD activity lead to further investigations of $\mathrm{H}_{2} \mathrm{O}_{2}$ levels in skeletal muscle during aging. $\mathrm{H}_{2} \mathrm{O}_{2}$ were elevated in the quadriceps muscle at 18 months compared to the younger 6 $(p<0.001), 12(p<0.001)$ and older $24(p=0.002)$ month old mice (Table 3 ).

\section{Discussion}

Sarcopenia has been described as a multifactorial syndrome developing from changes in muscle morphology, oxidative stress, inflammation, physical activity and nutrition [36]. The accumulation of ROS and evidence of oxidised proteins has been implicated in sarcopenic muscle, however the attenuation and suppression of this disease remains contradictory. The present study demonstrates a loss of skeletal muscle mass at 18 months that is indicative of sarcopenia. This sarcopenic muscle had elevated levels of $\mathrm{H}_{2} \mathrm{O}_{2}$ and low levels of the antioxidant enzymes, catalase and GPx. While the source of ROS in sarcopenic muscle remains relatively unknown, this study gives evidence for the NOX2 enzyme with an increase in the expression of the essential subunit components. This study also suggests a compensatory response to muscle insult with elevated levels of $\mathrm{O}_{2}{ }^{-}$and a decline in SOD1 protection and no further loss of muscle mass at 24 months.

The present study supports others who have demonstrated significant loss of skeletal muscle mass and cellular changes during aging [3,27,37]. Pansarasa et al. (1999) proposed that in humans, 65 years of age is the time of most significant change and associated damage in muscle [27]. Kimball et al. (2004) demonstrated age related decline in skeletal muscle mass at 18 months of age in mice and evidence of sarcopenia from 21-27 months of age [3]. Aging in general is associated with an increase in oxidative stress and steady rise over the lifespan [38]. Pansarasa et al. (1999) suggested a correlation between ROS activity and age related changes in human skeletal muscle [27], while a similar study by Mecocci et al. (1999) demonstrated age related oxidative damage and significant loss of muscle mass [39]. Studies to date, 


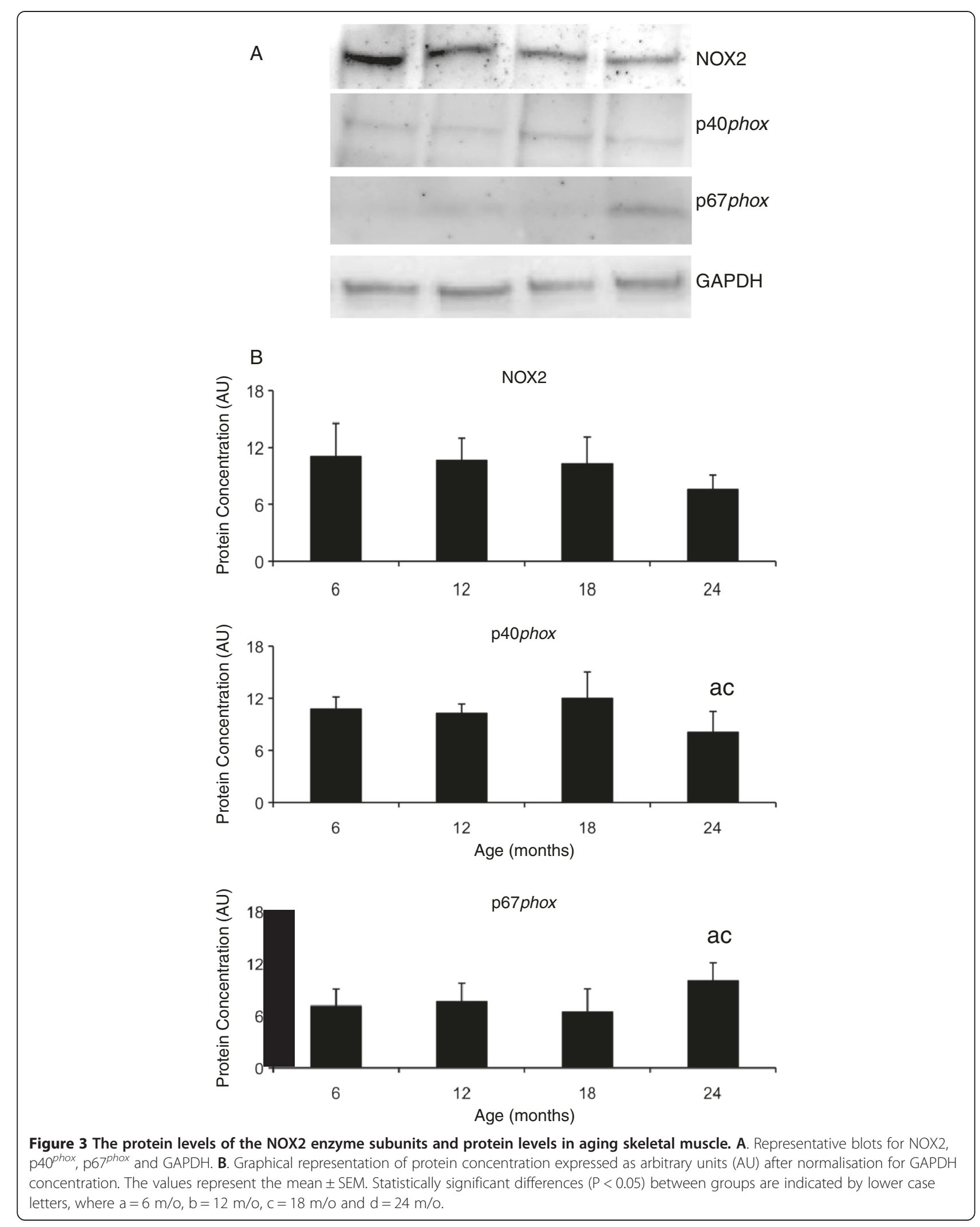


Table 3 Enzyme activity and hydrogen peroxide levels in aging skeletal muscle

\begin{tabular}{lcccc}
\hline & \multicolumn{3}{c}{ Age (months) } \\
\hline & $\mathbf{6}(\boldsymbol{n}=\mathbf{1 6})$ & $\mathbf{1 2}(\boldsymbol{n}=\mathbf{1 8})$ & $\mathbf{1 8}(\boldsymbol{n}=\mathbf{1 2})$ & $\mathbf{2 4}(\boldsymbol{n}=\mathbf{1 2})$ \\
SOD1 (U/mg protein) & $19.4 \pm 1.3$ & $9.1 \pm 0.3^{\mathrm{acd}}$ & $30.8 \pm 2.5^{\mathrm{abd}}$ & $25.9 \pm 1.3$ \\
SOD2 (U/mg protein) & $5.7 \pm 0.5$ & $5.7 \pm 0.4$ & $4.7 \pm 0.3$ & $3.4 \pm 0.1^{\mathrm{ab}}$ \\
GPx (U/mg protein) & $1.0 \pm 0.2$ & $1.1 \pm 0.1^{\mathrm{a}}$ & $0.7 \pm 0.1^{\mathrm{abd}}$ & $0.9 \pm 0.2$ \\
Catalase (U/mg protein) & $9.3 \pm 0.9$ & $12.1 \pm 1.2^{\mathrm{a}}$ & $8.8 \pm 1.2^{\mathrm{bd}}$ & $10.2 \pm 0.9$ \\
Hydrogen Peroxide $(\mu \mathrm{M})$ & $1.12 \pm 0.07$ & $1.16 \pm 0.04$ & $2.42 \pm 0.05^{\mathrm{abd}}$ & $1.74 \pm 0.06$ \\
Superoxide (AFU) & $8.1 \pm 1.3$ & $8.0 \pm 0.3$ & $8.9 \pm 1.1$ & $10.0 \pm 0.6^{\mathrm{ab}}$ \\
\hline
\end{tabular}

The values represent the mean \pm SEM.

Statistically significant differences $(P<0.05)$ between groups are indicated by lower case letters, where ${ }^{a} 6 \mathrm{~m} / \mathrm{o},{ }^{b} 12 \mathrm{~m} / \mathrm{o},{ }^{c} 18 \mathrm{~m} / \mathrm{o}$ and ${ }^{\mathrm{d}} 24 \mathrm{~m} / \mathrm{o}$.

have investigated models of sarcopenia using young and old animals for muscle comparison [29,39-41], whereas the present study investigated aging skeletal muscle with four age groups that represent the progressive aging process and development of sarcopenia.

The significant decline in skeletal muscle mass found at 18 months was matched by a marked increase in the mRNA expression of NOX 2 and $\mathrm{p} 40^{\text {phox }}$, compared to 6 and 12 months. These two subunits are absolutely necessary for the regulation, assembly and activation of the NOX2 enzyme and generation of $\mathrm{O}_{2}{ }^{-}$[42]. The increase in NOX was not matched by an increase in $\mathrm{O}_{2}{ }^{-}$, however further investigation in SOD1 activity suggests a well regulated antioxidant system in skeletal muscle at this time. The increase in $\mathrm{O}_{2}{ }^{-}$dismutation would indeed increase $\mathrm{H}_{2} \mathrm{O}_{2}$ levels in the cell and require antioxidant protection from catalase and GPx. However, despite the increase in $\mathrm{H}_{2} \mathrm{O}_{2}$ in skeletal muscle at 18 months compared to all other age groups, catalase and GPx appear to be unresponsive to the consequential increase in $\mathrm{H}_{2} \mathrm{O}_{2}$. The present study therefore gives evidence for antioxidant dysfunction during aging and at the onset of sarcopenia.

Increased levels of $\mathrm{H}_{2} \mathrm{O}_{2}$ have been found in aging skeletal muscle. Capel et al. (2004) demonstrated an increase in mitochondrial $\mathrm{H}_{2} \mathrm{O}_{2}$ release in the tibialis anterior (TA) muscles of 24 month old male Wister rats with sarcopenia when compared to 4.5 months [43], and this was later confirmed in the vastis lateralis muscle of elderly subjects [44]. Jackson et al. (2011) also demonstrated an increase in $\mathrm{H}_{2} \mathrm{O}_{2}$ levels in the gastrocnemius muscle of 18 and 24 month old mice when compared to the younger 6 months [45]. While Siu et al. (2008) found a similar increase in $\mathrm{H}_{2} \mathrm{O}_{2}$ levels in the gastrocnemius muscle of aged rats with significant loss of muscle mass, despite increased catalase activity [46]. Like these studies the present study supports $\mathrm{H}_{2} \mathrm{O}_{2}$ as a significant contributor in the development of sarcopenia.

A potential mechanism for $\mathrm{H}_{2} \mathrm{O}_{2}$, generated by $\mathrm{NOX}$, in the development of sarcopenia has been proposed. Sriram et al. (2011) recently reported a feed forward loop of Myostatin (Mstn) induced TNF- $\alpha$ and NOX generated $\mathrm{H}_{2} \mathrm{O}_{2}$ as a second messenger where TNF- $\alpha$ in turn increases the expression of Mstn via transcription factor nuclear factor kappa beta (NF-k $\beta$ ) [47]. Mstn is a known negative regulator of muscle growth. Overexpression of Mstn reduces muscle mass while Mstn deficiency has shown a 2 fold increase in muscle mass compared to wild types [48]. A recent study by McKay et al. (2012) demonstrated a 2 fold increase in myostatin mRNA levels in old muscle and suggests that myostatin impairs myogenic capacity in aged muscle [49]. In addition to the role of Mstn in sarcopenia, muscle wasting in sarcopenic rat muscle has been associated with increased Ubiquitin Proteasome System (UPS) activity [50]. Clavel et al. (2006) also reported increased UPS activity and expression of the atrophy related MuRF-1 and atrogin-1 genes in aged rat muscle that is suggested to be induced by TNF- $\alpha$ [51]. Furthermore, $\mathrm{H}_{2} \mathrm{O}_{2}$ has been shown to stimulate the UPS and expression of MuRF-1 and atrogin-1 in skeletal muscle myotubes [52]. Taken together, it is possible that $\mathrm{NOX}$ generated $\mathrm{H}_{2} \mathrm{O}_{2}$ acts as a second messenger for Mstn induced TNF- $\alpha$ and downstream regulation of the UPS in aging skeletal muscle sarcopenia.

However, $\mathrm{H}_{2} \mathrm{O}_{2}$ levels were not elevated in the quadriceps muscle at 24 months and there was no further loss of muscle mass. Instead, $\mathrm{O}_{2}{ }^{-}$levels were elevated in this muscle together with a decline in SOD1 activity. While this would suggest antioxidant dysfunction it is entirely possible that it is a regulated response to decrease $\mathrm{H}_{2} \mathrm{O}_{2}$ production and reduce further muscle wasting. Previous studies have demonstrated a compensatory mechanism in skeletal muscle that may occur in response to insult and the onset of muscle wasting. Edstrom et al. (2006) recently demonstrated a significant downregulation in atrophy related genes in sarcopenic skeletal muscle from 30 month old rats when compared to 4 and 12 months [53]. The potential decrease in muscle atrophy at 30 months could have been a compensatory response to earlier muscle loss that this particular study did not investigate. In further support of this, Kimball et al. (2004) found that while 
muscle mass began to decrease in rats beyond 21 months, markers of protein synthesis were elevated at 24 and 27 months of age [3]. A more recent study by Zhang et al. (2013), reported muscle weakness but no atrophy in 18 month old SOD1 deficient mice suggesting that SOD1 may be involved in muscle regenerative pathways [54]. Investigation into these complex systems in skeletal muscle would help to better understand the mechanisms involved in the development of sarcopenia.

The present study supports NOX2 enzyme involvement in the development of sarcopenia. The increase in the catalytic NOX2 enzyme subunit p67 $7^{\text {phox }}$ in skeletal muscle at 24 months suggests that the source of $\mathrm{O}_{2}{ }^{-}$ may be NOX2 generated. Like NOX2, NOX4 mRNA levels were also elevated in skeletal muscle at 18 months. In contrast to NOX2, NOX4 requires only $\mathrm{p} 22^{\text {phox }}$ for oxidase activation and generation of $\mathrm{O}_{2}^{-}[9,55]$ and does not appear to reside in the plasma membrane, rather its localization is within intracellular organelles and generates $\mathrm{O}_{2}{ }^{-}$intracellularly [56,57]. However, the localisation of NOX4 in skeletal muscle is yet to be defined and therefore its role in skeletal muscle aging remains unknown. It is also important to note that because the NOX4 enzyme potentially generates $\mathrm{O}_{2}{ }^{-}$within subcellular compartments, such as the endoplasmic reticulum, it is undetectable by DHE $[20,58]$. Indeed, an increase in NOX4-generated $\mathrm{O}_{2}{ }^{-}$production in intracellular organelles has the potential to cause considerable damage to cellular structures and has been suggested to contribute to cellular senescence [20]. The results from this study indicate the potential for NOX4 as a subcellular regulator of $\mathrm{O}_{2}{ }^{-}$and suggests further investigation into its localization and thereby its role in skeletal muscle and sarcopenia.

\section{Conclusions}

This study investigated oxidative systems in the development of sarcopenia in an otherwise healthy mouse model of aging. The time of significant change in skeletal muscle was at 18 months with an increase in NOX2 enzyme expression and levels of $\mathrm{H}_{2} \mathrm{O}_{2}$, antioxidant dysfunction and the onset of sarcopenia. However, while NOX2 enzyme expression was also increased in skeletal muscle at 24 months, $\mathrm{O}_{2}{ }^{-}$levels were elevated with SOD1 antioxidant dysfunction and maintenance of muscle mass. This study indeed supports oxidative changes in muscle during aging that may be both inductive of sarcopenia and a compensatory mechanism to maintain muscle integrity. This study suggests that elevated levels of $\mathrm{H}_{2} \mathrm{O}_{2}$ from NOX2 at 18 months, is a key component in the onset of sarcopenia. In contrast, the increase in $\mathrm{O}_{2}{ }^{-}$and decline in SOD1 activity at 24 months may be a regulated response to decrease $\mathrm{H}_{2} \mathrm{O}_{2}$ levels and further muscle insult. Furthermore, while this study suggests that $\mathrm{H}_{2} \mathrm{O}_{2}$ is the key oxidant in the onset of sarcopenia, the lack of antioxidant protection from catalase and GPx is equally as important, whereas the lack of SOD1 antioxidant protection at 24 months does not appear to contribute to sarcopenia.

\section{Competing interests}

The authors declare that they have no competing interests.

\section{Authors' contributions}

MJS-G participated in the design of the study, carried out the analysis and interpretation of data and drafted the manuscript. PAL participated in the design of the study, contributed to the interpretation of data and revised the manuscript. Both authors read and approved the final manuscript.

\section{Author details}

${ }^{1}$ School of Biomedical and Health Sciences, Victoria University, Melbourne, Australia. ${ }^{2}$ School of Medicine, Deakin University, Geelong 3217, Vic, Australia.

Received: 4 March 2013 Accepted: 30 September 2013 Published: 7 October 2013

\section{References}

1. Fulle $S$, et al: The contribution of reactive oxygen species to sarcopenia and muscle ageing. Exp Gerontol 2004, 39(1):17-24.

2. Mansouri A, et al: Alterations in mitochondrial function, hydrogen peroxide release and oxidative damage in mouse hind-limb skeletal muscle during aging. Mech Ageing Dev 2006, 127(3):298-306.

3. Kimball SR, et al: Assessment of biomarkers of protein anabolism in skeletal muscle during the life span of the rat: sarcopenia despite elevated protein synthesis. Am J Physiol Endocrinol Metab 2004, 287(4):E772-E780.

4. Short KR, et al: Impact of aerobic exercise training on age-related changes in insulin sensitivity and muscle oxidative capacity. Diabetes 2003, 52(8):1888-1896

5. Morley JE: Sarcopenia in the elderly. Fam Pract 2012, 29(suppl 1):i44-i48.

6. Castaneda C: Muscle wasting and protein metabolism. J Anim Sci 2002, 80:E98-E105.

7. Landi F, et al: Sarcopenia and mortality risk in frail older persons aged 80 years and older: results from ilSIRENTE study. Age Ageing 2013, 42(2):203-209.

8. Scandalios JG: Oxidative stress: molecular perception and transduction of signals triggering antioxidant gene defenses. Braz J Med Biol Res 2005, 38(7):995-1014.

9. Geiszt M: NADPH oxidases: new kids on the block. Cardiovasc Res 2006, 71(2):289-299.

10. Harraz MM, et al: SOD1 mutations disrupt redox-sensitive Rac regulation of NADPH oxidase in a familial ALS model. J Clin Invest 2008, 118(2):659-670.

11. Oudot A, et al: NADPH oxidases are in part responsible for increased cardiovascular superoxide production during aging. Free Radic Biol Med 2006, 40(12):2214-2222.

12. Wei YH, Lee HC: Oxidative stress, mitochondrial DNA mutation, and impairment of antioxidant enzymes in aging. Exp Biol Med 2002, 227(9):671-682.

13. Lambeth JD: NOX enzymes and the biology of reactive oxygen. Nat Rev Immunol 2004, 4(3):181-189.

14. Cheng $\mathrm{G}$, et al: Homologs of gp91phox: cloning and tissue epression of Nox3, Nox4, and Nox5. Gene 2001, 269(1-2):131-140.

15. Groemping $Y$, Rittinger $K$ : Activation and assembly of the NADPH oxidase: a structural perspective. Biochem J 2005, 386(Pt 3):401-416.

16. Mofarrahi $M$, et al: Regulation of proliferation of skeletal muscle precursor cells By NADPH oxidase. Antioxid Redox Signal 2008, 10(3):559-574.

17. Hamilton CA, et al: Superoxide excess in hypertension and aging - A common cause of endothelial dysfunction. Hypertension 2001, 37(2):529-534.

18. Rivera J, et al: Nox isoforms in vascular pathophysiology: insights from transgenic and knockout mouse models. Redox Rep 2010, 15(2):50-63.

19. Turgeon J, et al: Protection against vascular aging in Nox2-deficient mice: impact on endothelial progenitor cells and reparative neovascularization. Atherosclerosis 2012, 223(1):122-129.

20. Geiszt $M$, et al: Identification of Renox, an NAD(P)H oxidase in kidney. Proc Natl Acad Sci U S A 2000, 97(14):8010-8014. 
21. Paravicini TM, et al: Increased NADPH-oxidase activity and nox4 expression during chronic hypertension is associated with enhanced cerebral vasodilatation to NADPH in vivo. Stroke 2004, 35(2):584-589.

22. Nakayama $M$, et al: Increased expression of $\mathrm{NAD}(\mathrm{P}) \mathrm{H}$ oxidase in islets of animal models of Type 2 diabetes and its improvement by an AT1 receptor antagonist. Biochem Biophys Res Commun 2005, 332(4):927-933.

23. Chenevier-Gobeaux C, et al: Superoxide production and NADPH oxidase expression in human rheumatoid synovial cells: regulation by interleukin-1 $\beta$ and tumour necrosis factor-a. Inflamm Res 2006, 55(11):483-490.

24. Jiang $\mathrm{Q}$, et al: UV radiation down-regulates Dsg-2 via Rac/NADPH oxidase-mediated generation of ROS in human lens epithelial cells. Int J Mol Med 2006, 18(2):381-387

25. Ansari MA, Scheff SW: NADPH-oxidase activation and cognition in Alzheimer disease progression. Free Radic Biol Med 2011, 51(1):171-178

26. Ji LL: Antioxidant signaling in skeletal muscle: a brief review. Exp Gerontol 2007, 42(7):582-593.

27. Pansarasa $\mathrm{O}$, et al: Age-dependent changes of antioxidant activities and markers of free radical damage in human skeletal muscle. Free Rad Biol Med 1999, 27(5-6):617-622

28. Sentman $M-L$, et al: Phenotypes of mice lacking extracellular superoxide dismutase and copper- and zinc-containing superoxide dismutase. J BiO Chem 2006, 281(11):6904-6909.

29. Jang YC, et al: Dietary restriction attenuates age-associated muscle atrophy by lowering oxidative stress in mice even in complete absence of CuZnSOD. Aging Cell 2012, 11(5):770-782.

30. Jang $Y C$, et al: Increased superoxide in vivo accelerates age-associated muscle atrophy through mitochondrial dysfunction and neuromuscular junction degeneration. FASEB J 2010, 24(5):1376-1390.

31. Muller FL, et al: Absence of CuZn superoxide dismutase leads to elevated oxidative stress and acceleration of age-dependent skeletal muscle atrophy. Free Radic Biol Med 2006, 40(11):1993-2004.

32. Wei $Y$, et al: Angiotensin Il-induced NADPH oxidase activation impairs insulin signaling in skeletal muscle cells. J Biol Chem 2006, 281(46):35137-35146.

33. Serrander $L$, et al: NOX4 activity is determined by mRNA levels and reveals a unique pattern of ROS generation. Biochem J 2007, 406(1):105-114.

34. Williams IA, Allen DG: The role of reactive oxygen species in the hearts of dystrophin-deficient mdx mice. Am J Physiol Heart Circ Physiol 2007, 293(3):H1969-H1977.

35. Schmittgen T, et al: Quantitative reverse transcription-polymerase chain reaction to study mRNA decay: comparison of endpoint and real-time methods. Anal Chem 2000, 285(2):194-204.

36. Candow $D$, et al: Effect of nutritional interventions and resistance exercise on aging muscle mass and strength. Biogerontology 2012, 13(4):345-358.

37. Attaix $D$, et al: Altered responses in skeletal muscle protein turnover during aging in anabolic and catabolic periods. Int J Biochem Cell Biol 2005, 37(10):1962-1973.

38. Sundaram K, Panneerselvam KS: Oxidative stress and DNA single strand breaks in skeletal muscle of aged rats: role of carnitine and lipoicacid. Biogerontology 2006, 7(2):111-118.

39. Mecocci $P$, et al: Age-dependent increases in oxidative damage to DNA, lipids, and proteins in human skeletal muscle. Free Radic Biol Med 1999, 26(3-4):303-308

40. Ryan MJ, et al: Aging-dependent regulation of antioxidant enzymes and redox status in chronically loaded Rat dorsiflexor muscles. J Gerontol A Biol Sci Med Sci 2008, 63(10):1015-1026.

41. Ryan MJ, et al: Vitamin E and C supplementation reduces oxidative stress, improves antioxidant enzymes and positive muscle work in chronically loaded muscles of aged rats. Exp Gerontol 2010, 45(11):882-895.

42. Bedard K, Krause KH: The NOX family of ROS-generating NADPH oxidases: physiology and pathophysiology. Physiol Rev 2007, 87(1):245-313.

43. Capel $\mathrm{F}$, et al: Differential variation of mitochondrial $\mathrm{H} 2 \mathrm{O} 2$ release during aging in oxidative and glycolytic muscles in rats. Mech Ageing Dev 2004, 125(5):367-373.

44. Capel $\mathrm{F}$, et al: Due to reverse electron transfer, mitochondrial $\mathrm{H} 2 \mathrm{O} 2$ release increases with age in human vastus lateralis muscle although oxidative capacity is preserved. Mech Ageing Dev 2005, 126(4):505-511.

45. Jackson JR, Ryan MJ, Alway SE: Long-term supplementation with resveratrol alleviates oxidative stress but does Not attenuate sarcopenia in aged mice. J Gerontol A Biol Sci Med Sci 2011, 66A(7):751-764.
46. Siu PM, Pistilli EE, Alway SE: Age-dependent increase in oxidative stress in gastrocnemius muscle with unloading. J Appl Physiol 2008, 105(6):1695-1705.

47. Sriram S, et al: Modulation of reactive oxygen species in skeletal muscle by myostatin is mediated through NF-KB. Aging Cell 2011, 10(6):931-948.

48. Elkina $Y$, et al: The role of myostatin in muscle wasting: an overview. J Cachex Sarcopenia Muscle 2011, 2(3):143-151.

49. McKay BR, et al: Myostatin is associated with age-related human muscle stem cell dysfunction. FASEB J 2012, 26(6):2509-2521.

50. Altun $M$, et al: Muscle wasting in aged, sarcopenic rats Is associated with enhanced activity of the ubiquitin proteasome pathway. J Biol Chem 2010, 285(51):39597-39608.

51. Clavel $S$, et al: Atrophy-related ubiquitin ligases, atrogin-1 and MuRF1 are up-regulated in aged rat Tibialis Anterior muscle. Mech Ageing Dev 2006, 127(10):794-801

52. Li Y-P, et al: Hydrogen peroxide stimulates ubiquitin-conjugating activity and expression of genes for specific E2 and E3 proteins in skeletal muscle myotubes. Am J Physiol Cell Physiol 2003, 285(4):C806-C812.

53. Edstrom E, et al: Atrogin-1/MAFbx and MuRF1 are downregulated in agingrelated loss of skeletal muscle. J Gerontol Series A 2006, 61(7):663-674.

54. Zhang $Y$, et al: CuZnSOD gene deletion targeted to skeletal muscle leads to loss of contractile force but does not cause muscle atrophy in adult mice. FASEB J 2013, 27(9):3536-3548.

55. Ambasta $R$, et al: Direct interaction of the novel Nox proteins with p22phox is required for the formation of a functionally active NADPH Oxidase. J Biomed Chem 2004, 279(44):45935-45941.

56. Krause K: Aging: a revisited theory based on free radicals generated by NOX family NADPH oxidases. Exp Gerontol 2007, 42(4):256-262.

57. Martyn KD, et al: Functional analysis of Nox4 reveals unique characteristics compared to other NADPH oxidases. Cell Signal 2006 18(1):69-82.

58. Serrander $L$, et al: NOX5 is expressed at the plasma membrane and generates superoxide in response to protein kinase $C$ activation. Biochimie 2007, 89(9):1159-1167.

doi:10.1186/1471-2318-13-104

Cite this article as: Sullivan-Gunn and Lewandowski: Elevated hydrogen peroxide and decreased catalase and glutathione peroxidase protection are associated with aging sarcopenia. BMC Geriatrics 2013 13:104.

\section{Submit your next manuscript to BioMed Central and take full advantage of:}

- Convenient online submission

- Thorough peer review

- No space constraints or color figure charges

- Immediate publication on acceptance

- Inclusion in PubMed, CAS, Scopus and Google Scholar

- Research which is freely available for redistribution

Submit your manuscript at www.biomedcentral.com/submit
C BioMed Central 